\title{
The Hexopyranosyl Residue That Is $C$-Glycosidically Linked to the Side Chain of Tryptophan-7 in Human RNase $\mathrm{U}_{\mathrm{s}}$ Is $\alpha$-Mannopyranose ${ }^{\dagger}$
}

\author{
Tonny de Beer, $¥$ Johannes F. G. Vliegenthart,*, Andreas Löffler, ${ }^{\S}$ and Jan Hofsteenge ${ }^{\S}$ \\ Bijuot Center, Department of Bio-Organic Chemistry, Utrecht University, P.O. Box 80.075, NL-3508 TB Utrecht, \\ The Netherlands, and Friedrich Miescher-Institut, P.O. Box 2543, CH-4002 Basel, Switzerland
}

Received May 30, 1995; Revised Manuscript Received July 5, $1995^{\otimes}$

\begin{abstract}
Recently, the novel $C$-glycosidic linkage of a hexopyranosyl residue to the indole ring of tryptophan residue 7 of human RNase $\mathrm{U}_{\mathrm{s}}$ was reported [Hofsteenge, J., Müller, D. R., de Beer, T., Löffler, A., Richter, W. J., \& Vliegenthart, J. F. G. (1994) Biochemistry 33, 13524-13530]. Identification of this monosaccharide is a prerequisite for studies of its biosynthesis and its biological relevance. Using vicinal proton-proton coupling constants and rotating-frame nuclear Overhauser enhancements, we demonstrate that the $C$-linked substituent is $\alpha$-mannopyranose. Furthermore, the nuclear magnetic resonance (NMR) data indicate that the mannopyranose moiety in a glycopeptide derived from RNase $U_{s}$ adopts several conformations on the NMR time scale.
\end{abstract}

Glycosylation is one of the most common co- and posttranslational modifications of proteins and comprises a large variety of carbohydrates and amino acids covalently linked to each other. Well-known and widely occurring are $N$-glycosidic linkages between $N$-acetylglucosamine and Asn residues, $O$-glycosylation of Ser and Thr by $N$-acetylgalactosamine residues, and the occurrence of xylosylated Ser residues in the linkage region of proteoglycans (Lis \& Sharon, 1993). In addition, numerous other forms of $N$ - and $O$-glycosylation by single monosaccharides have been reported and comprehensively reviewed (Lis \& Sharon, 1993; Gooley \& Williams, 1994; Hayes \& Hart, 1994). Furthermore, linkages between carbohydrates and amino acids are formed in phenomena like ADP ribosylation ${ }^{1}$ (Stryer \& Bourne, 1986) and glypiation (Thomas et al., 1990) and in the nonenzymatic process glycation (Brownlee et al., 1988). Recently, we demonstrated the presence of a new type of covalent linkage between an aldohexopyranose and the side chain of Trp-7 in human RNase $U_{s}$, using a combination of mass spectrometry and NMR spectroscopy (Hofsteenge et al., 1994). Surprisingly, the hexopyranosyl moiety is not linked via an $N$ - or $O$-glycosidic linkage but is connected directly via its anomeric carbon to the $\mathrm{C} 2$ atom of the tryptophan side chain. Comparison of the ${ }^{1} \mathrm{H}$ and ${ }^{13} \mathrm{C}$ chemical shifts and the vicinal proton-proton coupling constants of the hexopyranosyl moiety with those of other

\footnotetext{
${ }^{+}$Part of this investigation was supported by the Netherlands Foundation for Chemical Research (SON) with financial aid from the Netherlands Organization for Scientific Research (NWO). A.L. is supported by a grant from the Deutsche Forschungsgemeinschaft.

* To whom correspondence should be addressed. Telephone: (31) (30) 2532168. Fax: (31) (30) 2540980

₹ Utrecht University.

Friedrich Miescher-Institut.

$\otimes$ Abstract published in Advance ACS Abstracts, September 1, 1995.

${ }^{1}$ Abbreviations: 1D, one-dimensional; 2D, two-dimensional; ADP, adenosine diphosphate; CID, collision-induced dissociation; FID, free induction decay; Fuc, L-fucose; Dol-P, dolichol phosphate; GDP, guanosine diphosphate; GlcNAc, D- $N$-acetylglucosamine; Man, Dmannopyranose; NMR, nuclear magnetic resonance; ROESY, rotatingframe nuclear Overhauser enhancement spectroscopy; WEFT, watereliminated Fourier transform; TPPI, time-proportional phase increment.
}

hexopyranoses (Bock \& Thøgerson, 1982; van Kuik et al., 1992) did not lead to a positive identification of the hexose (Hofsteenge et al., 1994). Herein, we show, using NMR spectroscopy, that the residue that is $C$-glycosidically linked to tryptophan- 7 in human $R$ Nase $U_{s}$ is $\alpha$-mannopyranose.

\section{MATERIALS AND METHODS}

The $C$-glycohexapeptide FTW ${ }^{\text {hex }}$ AQW $(5-10)$ was prepared as described previously. Briefly, the purified protein was reduced, carboxymethylated, and digested with thermolysin. Subsequently, the glycopeptide corresponding to residues 5-10 in the intact glycoprotein was purified by reverse phase HPLC (Hofsteenge et al., 1994).

NMR spectra were recorded with a Bruker AMX-600 spectrometer (Bijvoet Center, Department of NMR Spectroscopy, Utrecht University, or NSR Center, University of Nijmegen, the Netherlands) operating at a probe temperature of 290 or $295 \mathrm{~K}$. Prior to spectroscopic analysis, $180 \mathrm{nmol}$ of FTW ${ }^{\text {hex }} \mathrm{AQW}$ was repeatedly exchanged in ${ }^{2} \mathrm{H}_{2} \mathrm{O}(99.9$ atom $\%{ }^{2} \mathrm{H}$ ) with intermediate lyophilization and finally dissolved in $450 \mu \mathrm{L}$ of ${ }^{2} \mathrm{H}_{2} \mathrm{O}\left(99.96\right.$ atom $\left.\%{ }^{2} \mathrm{H}\right)$. $1 \mathrm{D}{ }^{1} \mathrm{H}-$ NMR spectra were recorded with a sweep width of 6000 $\mathrm{Hz}$ using a WEFT pulse sequence (Hård et al., 1992) and collecting 16-64 FIDs of $16 \mathrm{~K}$ complex data points each. Resolution enhancement was achieved by Lorentzian-toGaussian Fourier transformation, followed by a base line correction with a fifth order polynomial fit.

2D ${ }^{1} \mathrm{H}$-ROESY spectra (Bax \& Davis, 1985) were recorded with acquisition times of 12-24 h depending on the ROESY spin-lock pulse length, being $100 \mathrm{~ms}, 300 \mathrm{~ms}, 750 \mathrm{~ms}$, or $1.2 \mathrm{~s}$. In the $t_{1}$ dimension, 450 experiments were recorded using the TPPI method for quadrature detection (Marion \& Wüthrich, 1983), and 80-88 FIDs of 2048 complex data points each were collected per experiment. The ${ }^{1} \mathrm{H}$ carrier frequency was initially placed on the water resonance, and low-power $\mathrm{H}_{2} \mathrm{O}$ irradiation was applied during the relaxation delay of $1 \mathrm{~s}$. Before application of the spin-lock pulse, the ${ }^{1} \mathrm{H}$ carrier frequency was shifted to $5.4 \mathrm{ppm}$, thereby minimizing the Hartmann-Hahn transfer during the ROESY mixing time (Leeflang \& Kroon-Batenburg, 1992). 2D NMR 


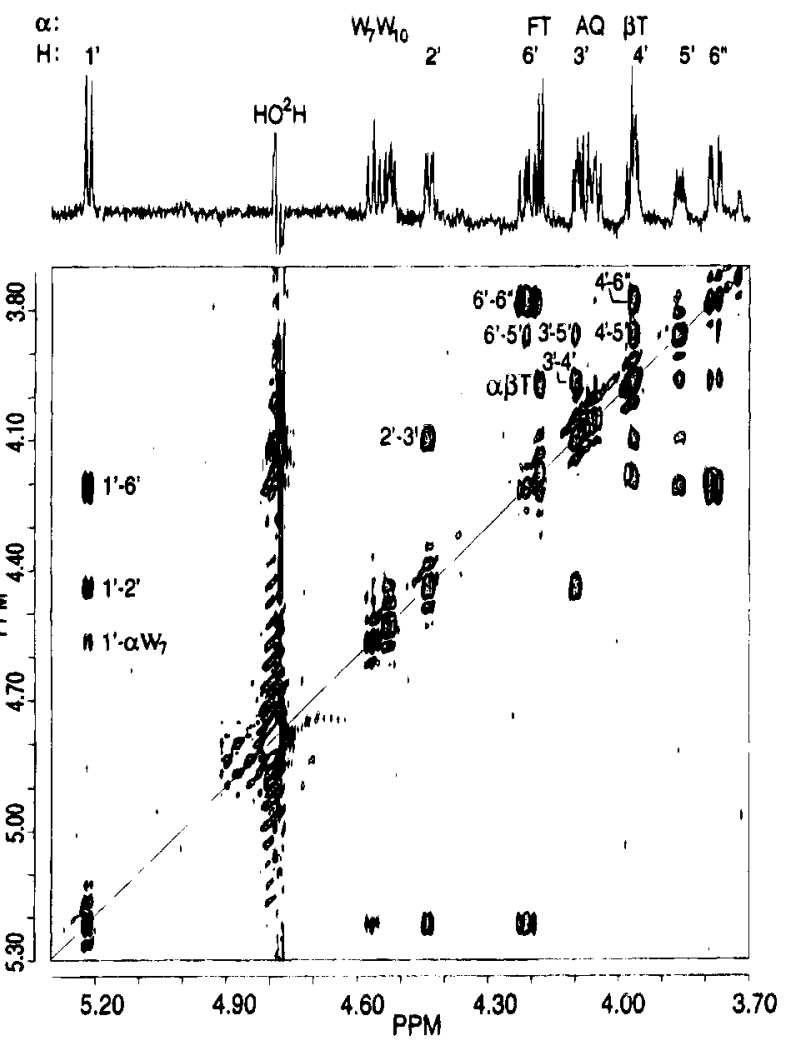

FIGURE 1: Part of the 1D 'H-NMR spectrum of FTW ${ }^{\mathrm{M} a n} \mathrm{AQW}$ (5$10)$ containing the resonances of the $C$-mannopyranosyl moiety. The notation is as described previously (Hofsteenge et al., 1994) and as depicted in Figure 2. Resonances of amino acid $\mathrm{H} \alpha$ protons and the $\mathrm{H} \beta$ proton of Thi- 6 of FIWM ${ }^{M} \mathrm{AQW}$ are also indicated. The corresponding part of a ROESY spectrum, recorded with a mixing time of $750 \mathrm{~ms}$, containing intraresidual ROEs of the hexopyranosyl moiety is also shown. ROESY cross-peaks are indicated with a pair of numbers, indicating the corresponding proton pair, whereas $u$ and $\beta$ represent amino acid $\mathrm{H} \alpha$ and $\mathrm{H} \beta$ protons, respectively.

data sets were processed with the Bruker UXNMR software package. Briefly, time domain data were multiplied with a phase-shifted squared sine bell function in both dimensions. The $1 \mathrm{~K} \times 1 \mathrm{~K}$ data set resulting after Fourier transformation and zero filling was base line corrected in both dimensions with fifth order polynomial fits.

\section{RESULTS}

The complete ${ }^{1} \mathrm{H}$ - and ${ }^{13} \mathrm{C}$-NMR assignment of the aldohexopyranosyl moiety in the $C$-glycopeptide FTW hex $_{-}$ $A Q W$, obtained from human $R N a s e U_{s}$, has been described previously (Hofsteenge et al., 1994). Interestingly, the ${ }^{13} \mathrm{C}$ chemical shift of the exocyclic hydroxymethyl carbon of the hexopyranosyl moiety $(\delta, 60.3)$ is found approximately 2 ppm upfield from those of hydroxymethyl carbons of D-hexopyranoses in the ${ }^{4} C_{1}$-chair conformation (Bock \& Thøgerson, 1982). A similar upfield shift has been observed for the hydroxymethyl carbon of $\alpha$-D-idopyranose, which adopts conformations with the hydroxymethyl group located nonequatorially (Snyder \& Serianni. 1986). In ROESY spectra of FTW ${ }^{\text {hex }} \mathrm{AQW}$, an intense ROE between $\mathrm{Hl}^{\prime}$ and one of the hydroxymethyl protons (cross-peak $1^{\prime}-6^{\prime}$ in Figure 1) is observed. The proximity of the $\mathrm{Hl}^{\prime}$ and $\mathrm{H6}^{\prime}$ protons indicates that the hydroxymethyl group is not in the usual equatorial orientation (i.e. compare Figure $2 \mathrm{~A}$ with Figure $2 \mathrm{C}$ ). The unusual contormation of the hexuse residue
A

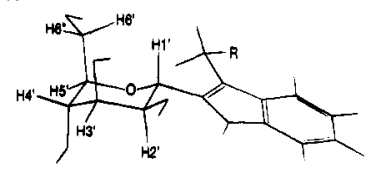

B

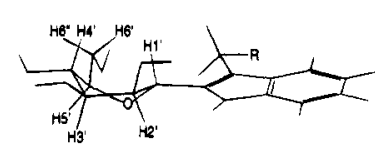

C

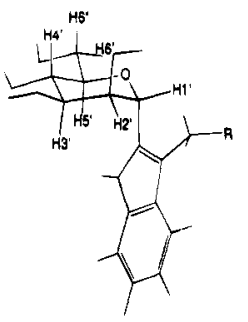

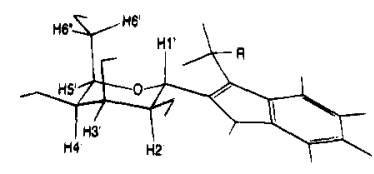

E

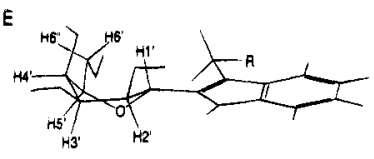

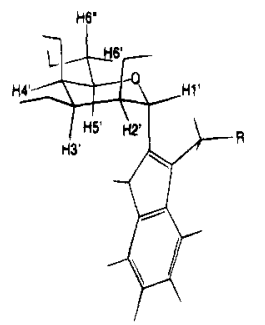

FIGUkE 2: $\alpha$-D-Mannopyranosyl $(\mathrm{A}-\mathrm{C}$ ) and $\alpha$-D-talopyranosyl (DF) moieties linked to the indole ring of $\operatorname{Trp}-7$ in a ${ }^{1} C_{4}$-chair conformation (A and D), a ${ }^{1} T_{3}$-twisted boat conformation (B and $\mathrm{E})$, and a ${ }^{4} C_{1}$-chair (C and $\mathrm{F}$ ) conformation. The pictures were generated on a Silicon Graphics 4D/35 workstation using the Insight software package. The $\alpha$-D-mannopyranosyl moiety is not present in a single conformation (see text), and the depicted conformations are only shown as clarification of the text. $R$ stands for the remaining part of the peptide FTW ${ }^{\text {Man }} \mathrm{AQW}$.

Table 1: NMR Data of the $C$-Mannopyranosyl Moiety in FTW ${ }^{\text {Man }} \mathrm{AQW}$ from Human RNase $\mathrm{U}_{\mathrm{s}}{ }^{a}$

\begin{tabular}{cclccc}
\hline & & & vicinal & \multicolumn{2}{c}{ nonvicinal ROEs } \\
\cline { 5 - 6 } proton & $\delta_{\mathrm{H}}$ & $J_{i, i+1}(\mathrm{~Hz})$ & ROEs $\eta_{i, i+1}$ & protons & $\eta$ \\
\hline $\mathrm{H} 1^{\prime}$ & 5.22 & 7.8 & $\mathrm{w}$ & $\mathrm{H} 1^{\prime}-\mathrm{H6}^{\prime}$ & $\mathrm{s}$ \\
$\mathrm{H} 2^{\prime}$ & 4.42 & 32 & $\mathrm{~s}$ & $\mathrm{H} 3^{\prime}-\mathrm{H}^{\prime}$ & $\mathrm{w}$ \\
$\mathrm{H} 3^{\prime}$ & 4.09 & 5.5 & $\mathrm{w}$ & $\mathrm{H} 4^{\prime}-\mathrm{H}^{\prime \prime}$ & $\mathrm{m}$ \\
$\mathrm{H} 4^{\prime}$ & 3.96 & 3.8 & $\mathrm{w}$ & & \\
$\mathrm{H} 5^{\prime}$ & 3.87 & 3.318 .3 & $\mathrm{~m} /$ n.d. & & \\
$\mathrm{H}^{\prime}$ & 4.21 & & & & \\
$\mathrm{H} 6^{\prime \prime}$ & 3.77 & & & & \\
\hline
\end{tabular}

" $\mathrm{H}$ chemical shifts (ppm), given at $300 \mathrm{~K}$ by reference to internal acetone $\left(\delta_{\mathrm{H}} 2.225\right)$, and homonuclear vicinal ${ }^{1} \mathrm{H}-{ }^{1} \mathrm{H}$ coupling constants (hertz) have been reported elsewhere (Hofsteenge et al., 1994). The notation for the mannopyranosyl moiety is depicted in Figure 2. ROE intensities were estimated from cross-peak volumes in 2D ROESY spectra (i.e. Figure 1) recorded with a mixing time of $300 \mathrm{~ms}, 750 \mathrm{~ms}$, or $1.2 \mathrm{~s}$ and were corrected for their offset to the carrier frequency (Leeflang \& Kroon-Batenburg, 1992). ROE intensities $(\eta)$ were determined as a percentage of the summed ROE and diagonal-peak intensities in a $\omega_{2}$-column of the appropriate line width and were classified as weak ( $w$, less than $5 \%$ ), medium (m, 6-10\%), or strong (s, more than $10 \%$ ) intensities. The classifications were identical for the three ROE mixing times; n.d. stands for not determined.

is also reflected in the set of vicinal proton-proton $\left({ }^{1} \mathrm{H}-\right.$ ${ }^{1} \mathrm{H}$ ) coupling constants (Table 1 ). In particular, the value of ${ }^{3} J_{3^{\prime} 4^{\prime}}$ of $5.5 \mathrm{~Hz}$ is incompatible with either of the usually favored ${ }^{1} C_{4}$ - or ${ }^{4} C_{1}$-chair conformations of aldohexopyranoses (Bock \& Thøgerson, 1982; Kochetkov et al., 1991; Lamba et al., 1993).

The ROE between the $\mathrm{HI}^{\prime}$ and $\mathrm{H}^{\prime}$ protons not only shows that the hydroxymethyl group is located predominantly nonequatorially but also shows that these protons are on the same face of the ring (Figure 2). By definition, this means that the hexopyranosyl moiety has an $\alpha$-configuration, regardless of it being the $L$ - or D-stereoisomer. To avoid confusion with nomenclature, the identification of the hexopyranosyl moiety is described assuming the D-config- 


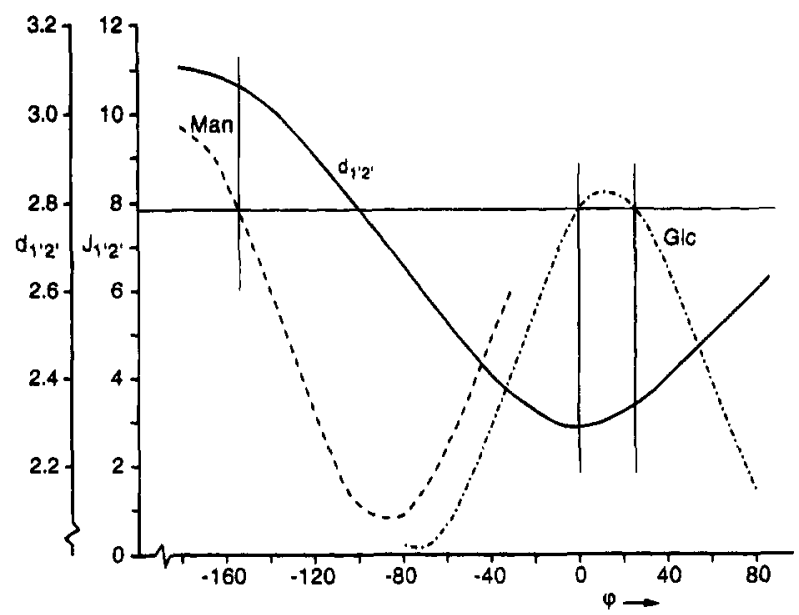

FIGURE 3: Coupling constants were calculated using generalized Karplus equations (Haasnoot et al., 1979) with the following electronegativity factors: 1.3 for oxygen, 0.4 for carbon, and 0.85 for nitrogen. One carbon and one nitrogen atom were used as $\beta$-substituents of the tryptophan $\mathrm{C} 2$ for the calculation of the $\mathrm{H}^{\prime}{ }^{\prime}-$ $\mathrm{H} 2^{\prime}$ curves. Karplus curves for the vicinal ${ }^{1} \mathrm{H}^{-1} \mathrm{H}$ coupling constant ${ }^{3} J_{1^{\prime} 2^{\prime}}$ are depicted for the range of possible dihedral angles $(\varphi)$ between $\mathrm{H} 1$ and $\mathrm{H} 2$ for the $\alpha$-D-gluco configuration and for the $\alpha$-D-manno configuration. Interproton distances $\left(d_{1^{\prime} z^{\prime}}\right)$ were determined as a function of the dihedral angle $\left(\varphi_{1^{\prime} z^{\prime}}\right)$ between these protons using a Silicon Graphics $4 \mathrm{D} / 35$ workstation with the Insight software package and the interproton distance $\mathrm{C} 2(\mathrm{H} 1, \mathrm{OH})-\mathrm{C} 3-$ $(\mathrm{H} 2, \mathrm{OH})$ in threitol as a model. The horizontal line indicates the value of the coupling constant $J_{1^{\prime} 2^{\prime}}(7.8 \mathrm{~Hz})$. Vertical lines represent dihedral angles consistent with this coupling constant, and the corresponding $\mathrm{H} 1-\mathrm{H} 2$ distance can be determined by the intersection with the $d_{1^{\prime} z^{\prime}}(\varphi)$ curve.

uration. The dependence of the vicinal ${ }^{1} \mathrm{H}-{ }^{1} \mathrm{H}$ coupling constant ${ }^{3} J_{1^{\prime} 2^{\prime}}$ on the dihedral angle between $\mathrm{H}^{\prime}$ and $\mathrm{H} 2^{\prime}$ was approximated for the gluco configuration and for its $\mathrm{C} 2$ epimer using a generalized Karplus equation (Haasnoot et al., 1979). Because of the steric properties of a sixmembered ring, only a limited range of dihedral angles is possible, and only for these ranges are the Karplus curves depicted (Figure 3). The same figure shows the variation of the distance between $\mathrm{H}^{\prime}$ and $\mathrm{H} 2^{\prime}$ with the dihedral angle to visualize the relation of the vicinal ${ }^{1} \mathrm{H}-{ }^{1} \mathrm{H}$ coupling constant with the interproton distance for the different configurations. For a gluco configuration, the large vicinal ${ }^{1} \mathrm{H}-1 \mathrm{H}$ coupling constant ${ }^{3} J_{1^{\prime} z^{\prime}}$ of $7.8 \mathrm{~Hz}$ can only result from small dihedral angles between these protons (Figure 3 ). This corresponds to an energetically unfavorable eclipsed conformation with, for instance, severe steric hindrance between the $2^{\prime}$-hydroxyl group and the tryptophan indole ring. More importantly, the short distance between the two protons accompanying these small dihedral angles would result in a very intense ROE (Figure 3). However, only a weak $\mathrm{HI}^{\prime}-$ $\mathrm{H} 2^{\prime}$ ROE (cross-peak $1^{\prime}-2^{\prime}$ in Figure 1) is observed in comparison with other ROEs (Table 1), and the possibility of the aldohexopyranose being glucose is therefore excluded. Consequently, the hexose must be at least a $\mathrm{C} 2$ epimer of glucose, being either mannose ( $\mathrm{C} 2$ epimer), altrose ( $C 2,3$ epimer), talose ( $\mathrm{C} 2,4$ epimer), or idose ( $\mathrm{C} 2,3,4$ epimer). For these configurations, the coupling constant of $7.8 \mathrm{~Hz}$ corresponds to a relatively large $\mathrm{H}^{\prime}-\mathrm{H} 2^{\prime}$ distance (Figure 3 ), consistent with the weak $\mathrm{H} 1^{\prime}-\mathrm{H} 2^{\prime}$ ROE (Table 1).

The ROE between $\mathrm{H}^{\prime}$ and $\mathrm{H}^{\prime}$ (cross-peak $3^{\prime}-5^{\prime}$ in Figure 1) indicates that these protons are located on the same face of the ring (Figure 2) and thereby excludes the possibility of the aldohexopyranose being altrose or idose. Regardless of the exact conformation(s) of the hexose, the $\mathrm{H}^{\prime}$ and $\mathrm{H}^{\prime}$ protons are relatively close to each other in the two remaining possible configurations, mannose (Figure $2 \mathrm{~A}-\mathrm{C}$ ) and talose (Figure 2D-F). This is indeed confirmed by the high intensity of the $\mathrm{H}^{\prime}-\mathrm{H}^{\prime} \mathrm{ROE}$ (Table 1), and the small vicinal ${ }^{1} \mathrm{H}-{ }^{1} \mathrm{H}$ coupling constant ${ }^{3} J_{2^{\prime} 3^{\prime}}$ of $3.3 \mathrm{~Hz}$ is also consistent with mannose or talose. The talo configuration does not allow a trans orientation for $\mathrm{H}^{\prime}-\mathrm{H} 4^{\prime}$, and consequently, these vicinal protons are at short interproton distances (i.e. Figure 3D-F). In fact, a coupling constant ${ }^{3} J_{3^{\prime} 4^{\prime}}$ of $5.5 \mathrm{~Hz}$ corresponds in the case of talose to a very short $\mathrm{H}^{\prime}-\mathrm{H}^{\prime}{ }^{\prime}$ distance, as estimated from the modified Karplus equation (Haasnoot et al., 1979). A similar reasoning can be used for the $\mathrm{H} 4^{\prime}-\mathrm{H} 5^{\prime}$ proton pair in talose, and these protons are also quite close to each other in each possible conformation (i.e. Figure $2 \mathrm{D}-\mathrm{F}$ ). However, both the $\mathrm{H} 3^{\prime}-\mathrm{H} 4^{\prime}$ and the $\mathrm{H} 4^{\prime}-\mathrm{H} 5^{\prime}$ ROEs are of weak intensity (Table 1), thereby excluding the possibility of talose. In contrast, in the manno configuration, conformations can exist with $\mathrm{H}^{\prime}$ relatively far apart from $\mathrm{H}^{\prime}$ and $\mathrm{H}^{\prime}$ (Figure 2A,B), consistent with the observed ROE intensities and the values of the coupling constants ${ }^{3} J_{3^{\prime} 4^{\prime}}$ and ${ }^{3} J_{4^{\prime} 5^{\prime}}$. Furthermore, the moderate intensity of the ROE between $\mathrm{H}^{\prime}$ and $\mathrm{H}^{\prime \prime}$ ' (crosspeak $4^{\prime}-6^{\prime \prime}$ in Figure 1; Table 1) shows that $\mathrm{H}^{\prime}$ ' is quite close to $\mathrm{H6}^{\prime \prime}$ (Figure 2), which corroborates the manno configuration. In summary, the hexopyranosyl residue which is $C$-glycosidically linked to the $\mathrm{C} 2$ carbon of the side chain of Trp-7 from RNase $U_{\mathrm{s}}$ is an $\alpha$-mannopyranosyl residue.

The vicinal ${ }^{1} \mathrm{H}-{ }^{1} \mathrm{H}$ coupling constants were converted into dihedral angles using modified Karplus equations (Haasnoot et al., 1979) parametrized for a $C$-glycosidically linked mannopyranose. Interestingly, the set of dihedral angles is not compatible with a single ring conformation, and consequently, the $C$-linked mannopyranosyl residue in FTW ${ }^{\text {Man }}$ AQW must exist in an ensemble of conformations on the NMR time scale, as observed previously for $\alpha$-D-idopyranose (Snyder \& Serianni, 1986) and $\alpha$-L-iduronic acid (Sanderson et al., 1987; Inoue et al., 1990). The observation of only a single set of chemical shifts means that the interconversion between these several conformations is fast. As a consequence, other NMR parameters such as the vicinal ${ }^{1} \mathrm{H}-{ }^{1} \mathrm{H}$ coupling constants and ROE intensities also have to be interpreted as population-weighted averages over all structures in the conformational ensemble. However, a quantitative interpretation of the ROE intensities and the coupling constants is hampered by the lack of knowledge of which conformers are actually involved in the population. Note that the ${ }^{1} C_{4},{ }^{3} T_{1}$, and ${ }^{4} C_{1}$ conformations depicted in Figure $2 \mathrm{~A}-\mathrm{C}$ are only meant to illustrate the identification of the monosaccharide moiety.

\section{DISCUSSION}

Application of "standard" monosaccharide analysis in order to identify the hexose moiety was unsuccessful, because of the stability of the $C$-glycosidic bond toward acid hydrolysis (results not shown). Furthermore, "hexose" ions or "hexose" fragment losses are absent in low-energy CID mass spectra, again due to the stability of the $C$-glycosidic bond (Hofsteenge et al., 1994), and consequently, identification of the monosaccharide moiety using this method is not possible. Although the flexibility of the hexosyl moiety in FTW ${ }^{\text {an }}$ AQW complicated the interpretation of the NMR 
spectra, its identity was unambiguously established as $\alpha$-mannopyranose by the combined use of coupling constants and ROE intensities. However, the current NMR data do not allow distinction between $\mathrm{D}$ - and L-mannopyranose. Comparison of chemical shifts and the ROEs that have been observed between the Man $\mathrm{H}^{\prime}$ and $\operatorname{Trp} \mathrm{H} \beta / \beta^{\prime}$ protons, between the Man $\mathrm{H}^{\prime}$ and $\operatorname{Trp} \mathrm{H} \alpha$ protons (Figure 1), and between the Man $\mathrm{H}^{\prime}$ ' and the indole NH protons (Hofsteenge et al., 1994) with those of the synthetic reference compounds, $C^{2}-\alpha$-D-mannopyranosyl-L-tryptophan and $C^{2}-\alpha-\mathrm{L}-C$-mannopyranosyl-L-tryptophan, will probably allow for determination of the absolute configuration.

D-Mannopyranose is a common monosaccharide constituent of $\mathrm{N}$ - and $\mathrm{O}$-linked oligosaccharide chains of glycoproteins in living organisms and is found in several types of protein-carbohydrate linkages (Krusius et al., 1987; Thomas et al., 1990; Herscovics \& Orlean, 1993; Lis \& Sharon, 1993; Lussier, 1995). It is usually present in a stable ${ }^{4} C_{1}$-chair conformation, in contrast to the $\alpha$-mannopyranosyl moiety in FTW ${ }^{\text {Man }} \mathrm{AQW}$. The instability of the ${ }^{4} C_{1}$-chair conformation arises most likely from the preference of the large, rigid tryptophan indole ring for an equatorial position, thereby minimizing steric interactions (i.e. compare (Figure $2 \mathrm{~A}$ and 2C). Another contribution believed to stabilize the ${ }^{4} C_{1}$-chair conformation is the anomeric effect (Lemieux \& Koto, 1974), which is absent in $C$-glycosides. Instead, electronic interactions of the ring oxygen electron clouds with those of the tryptophan ring might have considerable effects on the stability of the various conformations.

An equatorial position of the tryptophan side chain results in distortion of the ${ }^{4} C_{1}$-conformation and forces the hydroxymethyl group out of its preferred equatorial position (Figure 2A,B). A similar phenomenon has been observed for an anthraquinone-anthrone $C$-glycoside containing $\alpha$-Lrhamnopyranose (Adinolfi et al., 1991), which incidently has the identical ring configuration as $\alpha$-L-mannopyranose. Note that conformations with an axial position of the hydroxymethyl group, including the ${ }^{1} C_{4}$-chair conformation, are also destabilized by steric interactions (Figure 2A), and ring conformations seem to be mainly influenced by the conflicting preferences of the hydroxymethyl group and the indole ring for equatorial positions.

RNase $\mathrm{U}_{\mathrm{s}}$ predominantly bears the trisaccharide GlcNAc $\beta 1$ 4(Fuc $\alpha 1-6)$ GlcNAc at each of its five $N$-glycosylated Asn residues (Lawrence et al., 1993), which probably results from extensive trimming by exoglycosidases (Beintema et al., 1988; Aronson \& Kuranda, 1989). It cannot be ruled out that larger oligosaccharide structures were attached to Trp-7 and that the additional monosaccharide residues were removed from $\operatorname{Trp}^{\mathrm{Man}}$ by exoglycosidase activity as well.

The linkage between mannopyranose and the side chain of a tryptophan residue is unusual both in its constituents and in the $C$-glycosidic linkage between them and shows that there is an additional form of protein glycoslation. As previously noted, the occurrence of this modification is not limited to a single protein, a single tissue, or a single species (Hofsteenge et al., 1994), which suggests a conserved biosynthetic pathway. A neuropeptide from the stick insect Carausius morosus also contains a $\operatorname{Trp}^{\text {Hex }}$ residue (Gäde et al., 1992), although it has not been determined whether the substituent is also $C$-linked $\alpha$-mannopyranose. It is very interesting that the amino acid sequence of this neuropeptide shows no homology with that of the $C$-glycosylation site in human RNase $\mathrm{U}_{s}$, except for the obvious requirement of a Trp residue. Furthermore, $\operatorname{Trp}-10$ in RNase $U_{s}$ is not glycosylated, indicating a certain degree of specificity of the $C$-mannosylation process. It is therefore possible that conformation rather than the primary structure of the polypeptide determines the specificity of $C$-glycosylation of Trp residues.

It will be interesting to establish whether the chemistry of $C$-mannosylation of Trp residues is based on principles similar to those described for $\mathrm{N}$ - and $\mathrm{O}$-glycosylation, in which cases GDP-Man (in the Golgi) or Dol-P-Man (in the endoplasmic reticulum) are employed as immediate donors (Kornfeld \& Kornfeld, 1985; Herscovics \& Orlean, 1993; Lis \& Sharon, 1993; Lussier et al., 1995). The finding that UDP-glucose is involved in the biosynthesis of low-molecular mass $C$-glycosides in plants is thus far the only indication for the participation of phosphoester-activated sugars in protein C-glycosylation (Kerscher \& Franz, 1987; Kerscher \& Franz, 1988). In any event, the identification of the hexopyranosyl moiety as $\alpha$-mannopyranose is an important first step in the elucidation of the biosynthetic pathway of this unusual protein modification.

\section{ACKNOWLEDGMENT}

We thank Jerry Thomas for in-depth discussions and critical reading of the manuscript and Ingrid van Rooijen for preparing Figure 3.

\section{REFERENCES}

Adinolfi, M., Lanzetta, R., Marciano, C. E., Parrilli, M., \& de Giulio, A. (1991) Tetrahedron 47, 4435-4440.

Aronson, N. N., Jr., \& Kuranda, M. J. (1989) FASEB J. 3, 26152622.

Bax, A., \& Davis, D. G. (1985) J. Magn. Reson. 63, 207-213.

Beintema, J. J., Hofsteenge, J., Iwama, M., Morita, T., Ohgi, K., Irie, M., Sugiyama, R. H., Schieven, G. L., Dekker, C. A., \& Glitz, D. G. (1988) Biochemistry 27, 4530-4538.

Bock, K., \& Thøgerson, H. (1982) Annu. Rev. NMR Spectrosc. 13, $1-57$.

Brownlee, M., Cerami, A., \& Vlassara, H. (1988) N. Engl. J. Med. 318, 1315-1321.

Franz, G., \& Grün, M. (1983) Planta Med. 47, 131-140.

Gäde, G., Kellner, R., Rinehart, K. L., \& Proefke, M. L. (1992) Biochem. Biophys. Res. Commun. 189, 1303-1309.

Gooley, A. A., \& Williams, K. L. (1994) Glycobiology 4, 413417.

Haasnoot, C. A. G., Leeuw, F. A. A. M., \& Altona, C. (1979) Tetrahedron 36, 2783-2792.

Hård, K., van Zadelhoff, G., Moonen, P., Kamerling, J. P., \& Vliegenthart, J. F. G. (1992) Eur. J. Biochem. 209, 895-915.

Hayes, B. K., \& Hart, G. W. (1994) Curr. Opin. Struct. Biol. 4, 692-696.

Herscovics, A., \& Orlean, P. (1993) FASEB J. 7, 540-550.

Hofsteenge, J., Müller, D. R., de Beer, T., Löffler, A., Richter, W. J., \& Vliegenthart, J. F. G. (1994) Biochemistry 33, 1352413530.

Inoue, Y., Inouye, Y., \& Nagasawa, K. (1990) Biochem. J. 265, 533-538.

Kerscher, F., \& Franz, G. (1987) Z. Naturforsch. 42, 519-524.

Kerscher, F., \& Franz, G. (1988) J. Plant Physiol. 132, 110-115.

Kochetkov, N. K., Lipkind, G. M., Shashov, A. S., \& Nifantev, N. E. (1991) Carbohydr. Res. 221, 145-168.

Kornfeld, S. (1987) FASEB J. 1, 462-468.

Kornfeld, R., \& Kornfeld, S. (1985) Annu. Rev. Biochem. 54, 631664.

Krusius, T., Reinhold, V. N., Margolis, R. K., \& Margolis, R. U. (1987) Biochem. J. 245, 229-234. 
Lamba, D., Segre, A. L., Fabrizi, G., \& Matsuhiro, B. (1993) Carbohydr. Res. 243, 217-224.

Lawrence, C. W., Little, P. A., Little, B. W., Gluschka, J., van Halbeek, H., \& Alhadeff, J. A. (1993) Glycobiology 3, 249259.

Leeflang, B. R., \& Kroon-Batenburg, L. M. J. (1992) J. Biomol. NMR 2, 495-518.

Lemieux, R. U., \& Koto, S. (1974) Tetrahedron 30, 1933-1944.

Lis, H., \& Sharon, N. (1993) Eur. J. Biochem. 218, 1-27.

Lussier, M., Gentzsch, M., Scidu, A.-M., Bussey, H., \& Tanner, W. (1995) J. Biol. Chem. 270, 2770-2775.

Marion, D., \& Wuithrich, K. (1983) Biochem. Biophys. Res. Commlun. 113, 967-974
Sanderson, P. N., Huckerby, T. N., \& Nieduszynski, I. A. (1987) Biochem. J. 243, 175-181.

Snyder, J. R., \& Serianni, A. S. (1986) J. Org. Chem. 51, 26942702.

Stryer, L., \& Bourne, H. R. (1986) Annu. Rev. Cell. Biol. 2, 391419.

Thomas, J. R., Dwek, R. A., \& Rademacher, T. W. (1990) Biochemistry 29, 5413-5422.

Van Kuik, J. A., Hård, K., \& Vliegenthart, J. F. G. (1992) Carbohydr. Res. 235, 53-68.

B19511970 